\title{
WILLINGNESS TO USE MAAS IN A DEVELOPING COUNTRY
}

\author{
RODRIGO M. GANDIA ${ }^{1,2}$, FABIO ANTONIALLI ${ }^{2}$, JULIA R. OLIVEIRA ${ }^{1}$, JOEL Y. SUGANO ${ }^{1}$, ISABELLE \\ NICOLAÏ ${ }^{2} \&$ IZABELA R. CARDOSO OLIVEIRA ${ }^{1}$ \\ ${ }^{1}$ Federal University of Lavras, Brazil \\ ${ }^{2}$ University of Paris-Saclay, CentraleSupelec, France
}

\begin{abstract}
Mobility as a Service (MaaS) presents a shift from existing ownership-based transports and towards access-based ones and it has been recently gaining ground in urban mobility. MaaS is still surrounded by uncertainties and, its development and applicability are mainly centered in developed countries. However, MaaS is modular, adaptable and applicable to several realities. In this sense, this study aims to examine the perception of different transport models among students and to find the profile that can predict respondents' willingness to use MaaS in a developing country. This survey was applied to over 300 university students in a Brazilian city (Lavras). Using the CART algorithm, it was obtained classification trees to predict favourable responses related to MaaS use, based on several predictor variables (socio-economic characteristics, means of transport used, distance and other). It was observed that, car users are a little less sensitive to cost than non-car users. For car users, commute alternatives that take longer, with less flexibility and availability - even when offered at lower costs - are not appealing, while non-car users accept and spend more time whether lower costs are available. Also, in general, the treebased classification model predicted a positive adherence possibility for a MaaS scheme for both car users and non-car users (69\%). As conclusions, this study suggests a willingness to MaaS model for creating value for commuters in a developing country. It was found that many MaaS' characteristics (e.g. app payment, transport integration, monthly plan, customization, etc.) presented a positive predicted possibility of substitution, especially for millennials. Also, it was found that bicycle may be a modal that can be explored for MaaS schemes worldwide, and casual carpooling could be used as strategy to apply MaaS in places where the public transport lacks efficiency.

Keywords: Consumer behaviour, Mobility as a service, Travel behaviour, Tree-based classification model, Urban mobility.
\end{abstract}

\section{INTRODUCTION}

Urban mobility worldwide is suffering due to the crescent number of vehicles. In the course of the 20th century, the private car has become the dominant mode of transportation, fulfilling the growing needs of individuality, independence and flexibility ([1], [2]). At the same time, car-based transportation systems are responsible for a variety of negative environmental impacts, both on a global and local level such as; noise and air pollution, emission of greenhouse gases, traffic jams, road accidents, fragmentation of ecologically valuable land, increased health costs and hence contributes to climate change ([3], [4]). Thereby, urban mobility is suffering due to this rapid increase on vehicles' numbers, hence, the challenge now is to enhance mobility and accessibility while, at the same time, reducing congestion, road accidents and pollution in cities.

In this sense, the challenge is to enhance mobility and accessibility while, at the same time, reducing congestion, road accidents and pollution in cities. Given that, the realization of more environment-friendly transportation systems is now a worldwide goal ([5]-[7]). As alternative, shared mobility has the potential to reduce the private vehicle use and their negative environmental effects ([8]-[10]). In this sense, the concept of Mobility as a Service 
(MaaS) has been gaining ground in recent years and becoming a concrete market option, by presenting a shift away from the existing ownership-based transport system toward an accessbased one ([11], [6] ,[12], [13]).

The MaaS concept is fairly recent ([14]) and brings an innovative approach to traditional transport practices. However, MaaS is still surrounded by ambiguities and uncertainties, especially related to its main characteristics and use ([11]). Furthermore, most of MaaS deployments are mainly centred in developed countries with efficient transport systems ([11], [13]). On the other hand, we believe that MaaS is modular, adaptable and applicable to several realities. In this sense, an eventual MaaS user (in any given context) should perceive a level of value that surpasses vehicle ownership or any other utilized transport mode.

Although there are still gaps in its theoretical field, there is a consensus related to its key concept, which is to offer tailored-made on-demand integrated mobility solutions based on users' needs ([15], [6], [16], [11], [17]). MaaS is a user-centered service ([18]), this approach places the user as central to aspects related to mobility, as pointed out by Hannon et al. [19], the individual traveller is at the heart of this evolution, so consumers need to be open to adopting new technologies and services. Nevertheless, "there is very limited insight to date in terms of the behavioural impact of MaaS or its future potential" ([20]). In addition, studies on consumer behaviour and MaaS usage are still incipient as well as the fact that research on MaaS in developing countries have not yet been found in the literature [21].

Early adopters of MaaS are expected to be comprised of younger generations (Gen-Z and Millennials) because of their commute patterns - flexible travelers, who combine different modes of transport to make their trips ([23]). Mostly of university and college students can be comprehended as belonging to Gen-Z or Millennials, in this sense, it is important to understand the willingness to use MaaS from this group in order to comprehend whether MaaS can be achieved, by the consumer perspective, in a developing country.

Given the aforementioned the following questions were raised as guidelines for the present study: Which are the main characteristics of transport modes valued by university students? Is there willingness for MaaS among university students from a developing country? Which are the profiles more susceptible to use a MaaS scheme among those students? In this sense, this study aims to examine the perception of different transport models among students and to find the profile that can predict respondents' willingness to use MaaS in a developing country. This paper provides as a first step, some insights to implement a MaaS scheme in a developing country, understanding the user-perspective.

\section{RESEARCH METHODOLOGY}

With the aim of identifying the perception of different transport modes among students and to find the profile that can predict respondents' willingness to use MaaS in a developing country, this study is characterized as quantitative of descriptive and exploratory nature. Figure 1 presents the detailed research carried out.

The survey was applied to university students enrolled in the second academic semester of 2018 , in Lavras - Brazil. This city (approximately 100,000 inhabitants) was chosen as a study object given its peculiar mobility features. Due to the high number of university students the act of casual carpooling is common practice on their daily commute, especially in the public university which institutionalized this practice. Casual carpooling consists in the act of informal carpools for purposes of commuting and can be understood as a variation of hitchhiking for urban areas ([23]-[25]). Their essential idea is to provide a free ride for a passenger in order to complete idles seats in the car. The campus of public university counts with five stops for casual carpooling, which all have different destinations in the city. 


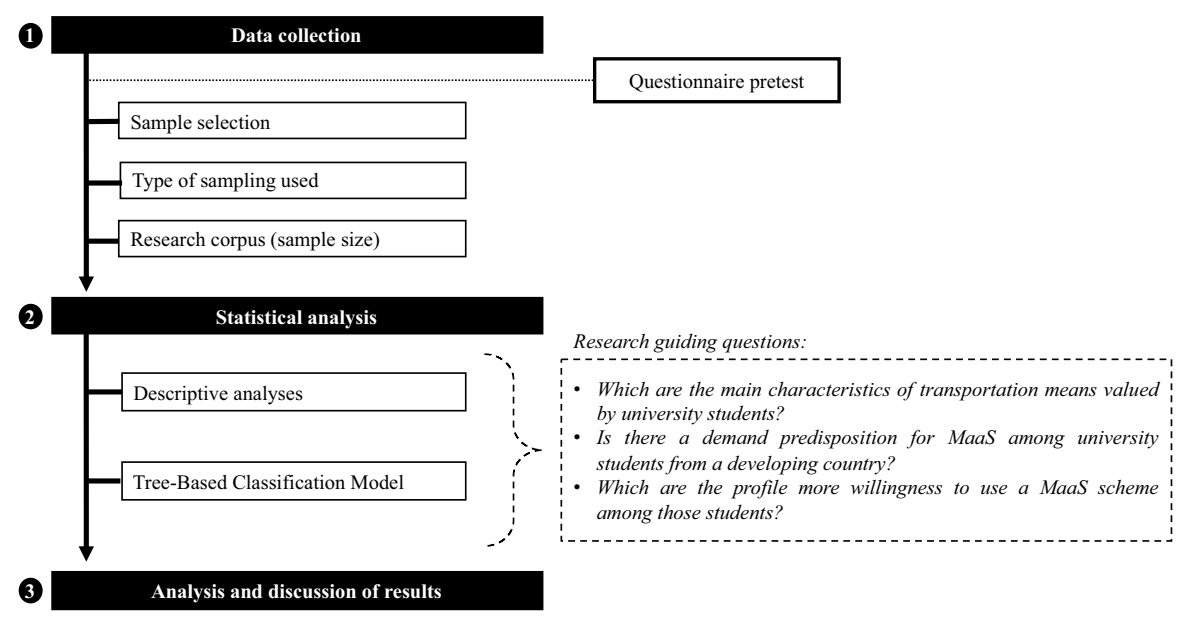

Figure 1: Research design.

Data collection (First step, Fig. 1) was done by a cross-sectional survey through a questionnaire applied among students of all Higher Education Institutions (HEI) (1 public and 3 private) in the city. The non-probabilistic sampling ([26]-[28]) was used with a final sample of 307 participants. Despite being a narrow segment of the entire population, our target population (university students) provides interesting insights as potential users of MaaS. The questionnaire used consisted mainly of qualitative questions. Individual characteristics, their motivations for choosing some transportation means and predisposition for sharing were investigated.

Step 2 consisted in statistical analyses. We used descriptive statistics and the CART treebased classification algorithm ([29]). The analyses were performed in R ([30]) using the rpart ([31]) and rpart.plot ([32]) packages. The sample was divided into two distinct groups within the transport modes commute, (1) with car ownership and (2) without car ownership.

In order to answer our first guideline question (which are the main characteristics of transport modes valued by university students?) descriptive analyses was used. Furthermore, the other guidelines questions (is there willingness for MaaS among university students from a developing country? and which are the profiles more susceptible to use a MaaS scheme among those students?) it was used descriptive and tree-based classification models.

Classification trees are used as exploratory analysis or to predict a categorical response (in our case, a binary variable with answers Yes and No) based on several predictor variables. This Machine Learning technique (Classification trees) is particularly useful when there are a large number of predictors in the dataset. In these situations, model-based approaches may fail, in addition to being restrictive in distributional assumptions and inference may be affected because of nonprobability sampling.

The tree is obtained by splitting the data repeatedly into two mutually exclusive groups based on the variable in the node. The division starts with the "root node", with the variable which explains most of the variability in the data, and it is applied to the subsequent nodes until the final ones. The partitions are interpreted from top to bottom, where the left paths indicate that the condition on each node (variable) has been fulfilled for the sample. The result is an intuitive and easy-to-interpret structure, which provides visual insights about associations between predictors and response. 
Classification trees were used to understand the predisposition to use MaaS and the profiles more willingness to use MaaS from both the perspective of users with and without car ownership (one tree for each group). Our objective is to analyse the conditions of appropriation of MaaS and thus to examine the conditions of its acceptability. From this perspective we place ourselves in the paradigm of the analysis of the diffusion of innovations ([33], [34]) and identify the perceived usefulness of MaaS (with performance expectancy variables as costs, travel time, flexibility, multiple transport modes, safety, etc.) and the perceived ease of use it taking into account the social influence and effort expectancy to use MaaS (see Dantan et al. [35] for a presentation of how the individual choices of users are taken into account in the acceptability of a mobility innovation).

As MaaS is a fairly recent concept ([14]), many of the survey participants might not have been familiar with it. Thus, it was used in single statements (that were presented to the respondents) a compilation of features inherent from MaaS platforms. The following variables were considered as predictors or moderators: age, sex, income, marital status, study day-time, driver's license possession, distance from the institution, monthly expenses with transportation, commute weekly frequency and, type of institution (public or private). At last, step 3 in Figure 1 consisted of the analysis and discussion of results.

\section{ANALYSES AND RESULTS}

The average age range for car users were 25 years old while for non-users was 22 . As for gender, numbers were similar for men and woman (141 and 166 responses, respectively). As our sample comprised of university students, the majority of respondents were single (282), with only 22 married and 2 divorced.

\subsection{Tree-based classification models}

MaaS is still an incipient concept, which many users might not be familiar with. Thus, for the construction of the trees it was use a compilation of characteristics present in a MaaS scheme, in the same statement. Thus, users were asked if they would change their private vehicle (tree model \#1) or would no longer purchase a private vehicle (tree model \#2) for a "means of transport that would integrate multiple transport modals on a single platform (mobile app) and charge a monthly plan for it". Still, it is noteworthy that, in order to reach greater assertiveness, characteristics such as; "payment via app", "monthly plan", "transport integration", and, "customized" were analysed separately for users with and without car ownership (Table 1).

It was observed that all MaaS' characteristics presented positive results regarding the willingness to use it.

Table 1: Willingness to use MaaS scheme based on their characteristics.

\begin{tabular}{ll|l}
\hline & With car ownership & Without car ownership \\
\hline MaaS characteristics & & \\
Payment via App & $71.79 \%$ & $68.04 \%$ \\
Monthly plan & $69.23 \%$ & $69.41 \%$ \\
Transport integration & $79.49 \%$ & $85.39 \%$ \\
Customized & $79.49 \%$ & $84.93 \%$ \\
\hline
\end{tabular}




\section{Tree \#1: Willingness to use MaaS from user with car ownership}

As depicted by Figure 2, in general, 69\% of car owners were willing to use a MaaS scheme. Five splitting variables were identified: (1) income, (2) weekly commute frequency, (3) lone commutes, (4) day/night study-shift and (5) transportation expenses.

It was observed that the profile most likely to use MaaS schemes are commuters with intermediate income rates that use their cars 3 times or less per week (100\% of cases). On the other hand, it was observed that commuters with intermediate income rates, with higher frequencies of car usage (superior than 3 times a week) and that are used to commute alone (especially in the night-shift) present lower adherence and less willingness towards MaaS schemes (only $17 \%$ of cases).

\section{Tree \#2: Willingness to use MaaS from users without car ownership}

As observed in Figure 3, similarly to results obtained on Tree \#1 in general, users without car ownership have also presented a high willingness to use MaaS schemes (69\% of respondents). For this second model, eight splitting variables were identified: (1) distance travelled [daily average], (2) main transport mode, (3) car purchase intent, (4) gender, (5) age, (6) casual carpooling habit, (7) day/night study shift and (8) transportation expenses.

In the case of users without car ownership, it was observed that those who travel daily between 1 and $4 \mathrm{~km}(3,4,5)$, who already own a car (but not as the main means of transport) or those who intend of buying a car and that have monthly transport expenses of more than 30 euros present $100 \%$ of willingness to MaaS models. On the other hand, users with monthly transport costs of less than 30 euros, intermediate commute distances, who already own a car (or those who intend to buy one) and with predominant commuting habits during the night shift, presented only $14 \%$ of willingness towards models of MaaS (most negative profile among the sampled users).

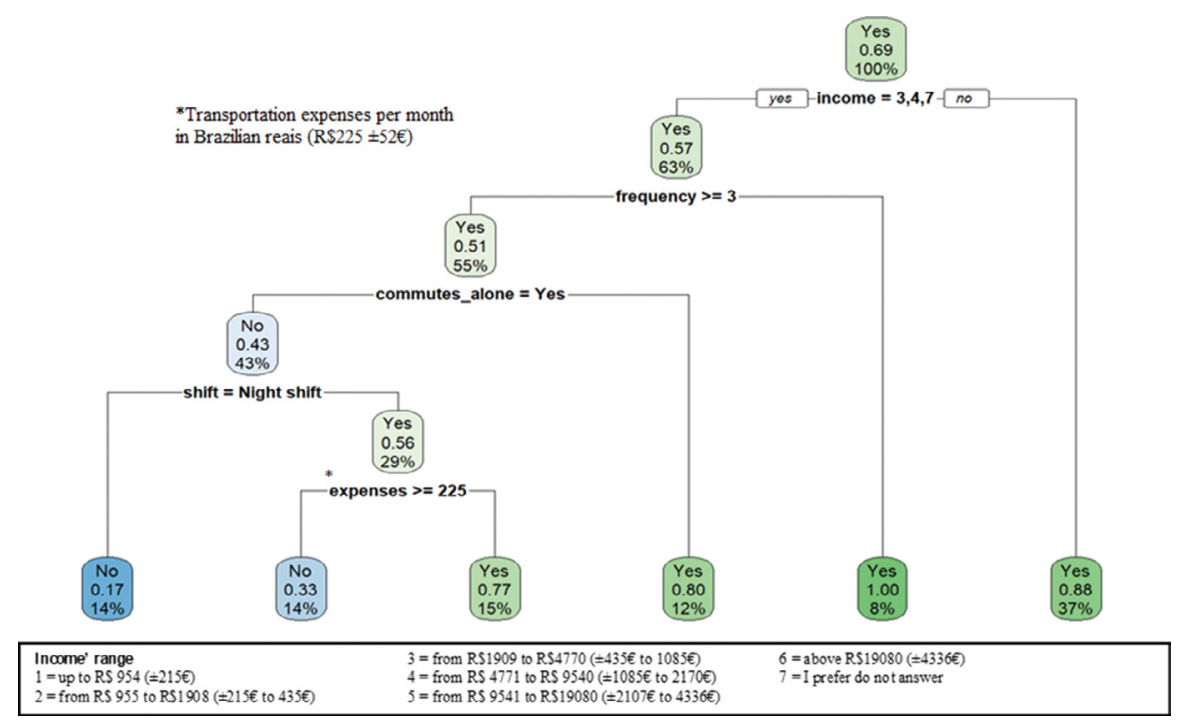

Figure 2: Willingness to use mobility as a service from users with car ownership. 


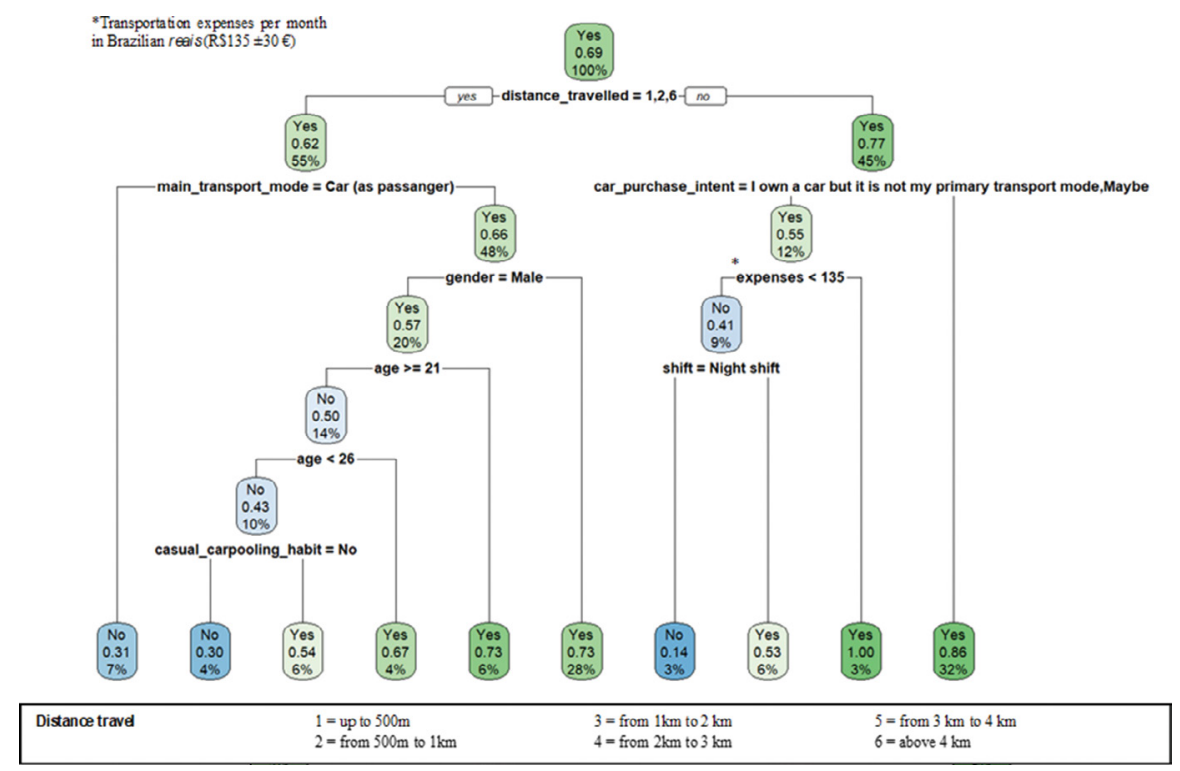

Figure 3: Willingness to use MaaS from users without car ownership.

\section{DISCUSSION}

A MaaS scheme consists of different modes of transport to provide an integrated mobility service for the user. ([11], [13]). In this sense, map the motivating factors and barriers to the use of transport mode by users is to understand the specificities to be eventually inserted in a MaaS scheme.

From our analysis, it was identified two categories of transport modes: users who own cars and those who do not. In the first category, the driver may choose not to share their vehicle or to do so (as a driver). In the second category, 5 options were identified, car (as a passenger), motorcycle, bus/shuttle, walking and bicycle. It is worth highlighting that a car owner, may also opt to use any of the categories identified for the non-drivers.

For each mode the main benefits and barriers to their use were identified from the users' reports. It was identified that there are distinct behaviours between whether or not to share a vehicle. It was considered that environmental factors and personal motivations may be responsible for this transition, as well as other unknown factors. In addition, sharing a car (as a driver) has motivations and demotivation that were not analysed because it is not part of the scope of this work.

At last, it was understood that it is necessary to analyse the impact of each transport mode in a MaaS model based on urban mobility issues that such given a mode entail. Thus, it was considered that car ownership presents higher issues for urban mobility than non-ownership. Among the alternatives, the worst scenario for urban mobility is a given user that owns a car and is not open to share it. In this sense, users who own the car but are open to sharing, and those who do not own the car, and use any of the other alternatives, present less harmful measures for urban transport. 
Given the aforementioned and based on the importance of the transport mode choice, presented as the result of a survey with over 300 students (see Gandia et al. [36]), Figure 4 depicts the higher and lower factor indicated in our results for each mode of transport based in a spectrum indicating the urban mobility issues.

Looking at Figure 4, it was understood that the real challenge is to implement a solution that better satisfies the mobility needs than the usage of a private car. The factors that discourage users from using transport modes with less impact on urban mobility (carsharing, motorcycle, bus/shuttle, walking, bicycle) are mostly related to availability, agility and parking difficulties. A MaaS scheme seeks to contribute exactly with solutions in optimizing the availability and agility of the search for the most appropriate transport mode with the aid of ICTs. Is worth to highlight that, we use in the paper the term agility to refer to the question of an actor's ability to change in systemic and uncertain contexts ([37]). That is why we will retain the agility definition of Dove [38]: "Being Agile means being proficient at changeand allows an organization to do anything it wants to do whenever it wants to."

According to Kamau et al. [39], on public transport - despite of more being affordable users face less comfort and more time constraints than private car users. Thus, even with individual car ownership being one of the most comfortable options for those who can afford it, MaaS schemes will help to contribute by minimizing the shortcomings of using other transport modes.

However, as postulated by Hietanen [14], a MaaS scheme is not suited for all user groups. Therefore, it is important to understand exactly the predisposed profile to use MaaS in order to start implementing a model from the most suitable users. Thus, based in the outputs of figures 2 and 3, in order to summarize our results, Figure 5 brings the visual representation of the determinant variables for the use of MaaS and the profile of users with greater willingness to its use, both for users with and without car ownership.

When it comes to adherence to a MaaS model, it was observed that the night shift of studies had negative influences for both groups of commuters. In the same way, transport expenses influenced both profiles, while higher commute expenses negatively reflected the model for drivers, lower transport expenditures positively influenced the MaaS adherence regarding non-drivers.

Also, shared travel habits of users for both groups influence the willingness to MaaS. At last, it was observed that car owners that do not use their cars on a daily basis, are more willing to take part in a MaaS scheme, as well as for those users that do not own vehicles, and that have a daily commute of intermediate distances, are also more prone to MaaS schemes.

\section{Modes of transport for urban commute}

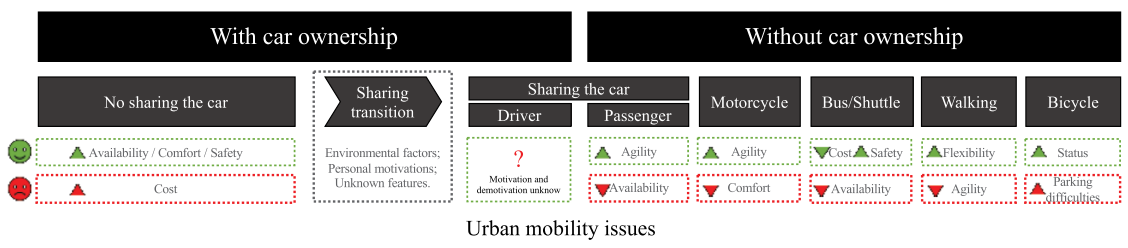

Figure 4: Impact of transport modes on urban mobility. 


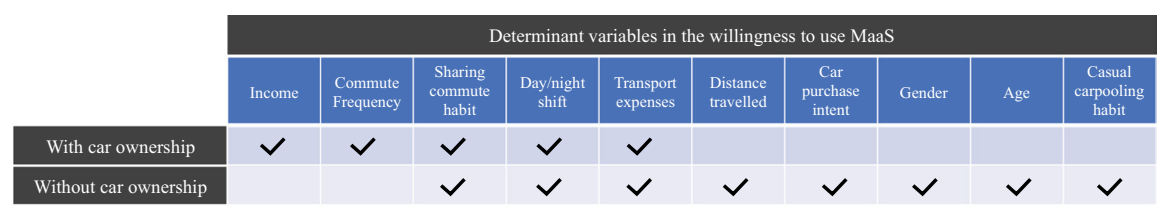

\section{General users' profile willing to use a MaaS scheme}
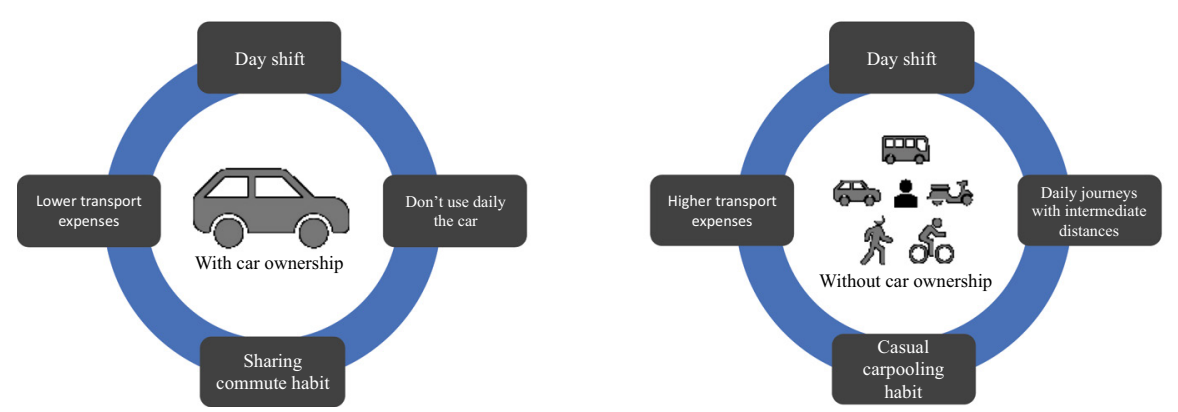

Figure 5: Determinant variables for a MaaS scheme for the selected user groups.

\section{CONCLUDING REMARKS}

MaaS seeks to integrate on-demand commute via bundled offerings of public and private transportation on a single platform. However, as far as we know, MaaS studies have only been carried out in developed countries - with efficient public transport networks ([11], [13]). Consequently, it was observed a gap with regards to both academic studies and practical deployment of MaaS schemes in developing countries.

By the results obtained in this study, it was observed the willingness to use MaaS schemes among commuters in a developing country. In fact, there is a big challenge to offer seamless transportation in a country where public transport is inefficient.

That is because the current and real situation of MaaS implementation in Brazil is far from reach even its early stages. Firstly, although there are huge disparities among regions, several steps of infrastructure development and regulatory frameworks in the foundation layer must be consolidated such as physical and digital infrastructure; land use and planning; re-orientation of regulatory frameworks to reflect changes in demands in human behaviour to encourage active travel and more flexible use of mobility modals. Secondly, it must be stimulated new array of mobility providers including traditional public/mass transit services, alongside private, shared, ride-hailing and micromobility services.

And finally, at the level of intermediation layer with the end-users, investments in MaaS platform providers for providing the best possible information on journey options (price, speed, modes and routes) must be considered, in order to ideally reach seamless purchasing end-to-end journeys, incorporating local charges and regulations.

Nevertheless, MaaS is modular and adaptable and can be implemented to any context as long as users (commuters) perceive value.

The results pointed out by Trees \#1 and \#2 displayed a general 69\% of adherence rate from both car users and non-car users towards MaaS. Considering that the average age of our sample was between 22 and 25 years-old, it can be inferred that MaaS in a developing country has a positive acceptance from Millennials, corroborating with ([22]). Furthermore, perceived value is different between various categories of users : analysis of early adopters of 
MaaS and motivations (pp. 84 "understanding maas book"). When it was analysed isolated characteristics such as: app payment, transport integration, monthly plan and customization, results presented a positive probability of substitution for car users and non-car users.

Thus, while income has a predictive impact on car users, the daily distance travelled is the variable that exerts most influence on non-car users. Factors such as day/night study-shift, transportation expenses, vehicle ownership, gender, age, casual carpooling habit and main transport mode used, had positive and negative impacts on the prediction of willingness to use MaaS.

It was observed distinctions among users with and without car ownership when it came willingness to use a MaaS scheme. In this sense, two general users' profiles were found: (1) users with car ownership are more willingness to use a MaaS scheme if they (a) do not use daily the car; has (b) sharing commute habit; has (c) lower transport expenses; and (d) mostly commute in day shift. On the other hand, (2) users without car ownership are more willingness to use a MaaS scheme with (a) higher transport expenses, (b) daily journals with intermediate distances; (c) casual carpooling habits; and also, (d) mostly commute in day shift.

Gandia et al. [36] states that among car users, the commute alternatives that take longer, with less flexibility and availability - even when offered at lower costs - were not appealing. Corroborating with this, car users pointed out availability, comfort and safety as the most important characteristics in the choice of car. Also, the status was not signalized as representative for the car's choice. In this sense, a MaaS model that delivers more availability, safety and comfort transport modals' choices may be an option for car users in a developing country.

Regarding non-car users, it was observed that features related to "availability, agility and parking difficulties" discourage the users. For instance, the casual carpooling and bus's transport modals are alternatives that provide solutions in cost and agility, however the lack of availability discourages their use.

Also, a recent study show that casual carpooling modal can be a strategic alternative to address the lack of public transportation efficiency in developing countries ([36]). Corroborate with this, it was observed that the lack of availability should be solved in order to address motivation to use both of those transport modals.

In addition, another transport modal for MaaS schemes that could be explored in a developing country is the bicycle, especially as a solution for first- and last-mile ([40]). Such transport modal is still neglected by most of MaaS studies ([41]). It was observed that users of bicycles believe that this modal deliver status, in addition to a perception of care with health and sustainability. In this sense, if a MaaS scheme provide certain strategies to improve the parking difficulties for bikes, that transport modal can strengthen MaaS schemes. These facts reinforce the analysis of the motivational factors that have been highlighted in the literature (see J. Schikofsky, et al. 2020).

It was found that the dematerialization phenomena are perceived as positive for urban mobility users in our sample. The fact that transport is dematerialized, and it is presented as a mobile app, shows real perceived value in a considerable group of car users and non-car users. Peer to peer business models, such as Uber, Cabify and others are already playing an important role towards transport dematerialization, and this can a reshaping effect on the way commuter relate to transportation means - similarly to what has occurred to the music dematerialization phenomenon ([42]). However, is worth highlighting that transport modes, specifically in MaaS schemes, present complex distinctions that were not analysed in this study.

In this aspect, it is important to address the limitations of this paper about the notion of MaaS' concept among youngers in the countryside city of Brazil. The wide range of MaaS 
services offered to the users can put in difficult of its understanding by the interviewers, which may have a simplistic view of such a complex system. This may result in a reductionism of trade-off among existing modal modes, which is certainly not the whole comprehension of the concept of MaaS. And also, it can be considered that perhaps the lack of alternatives of public transportation services may be affecting positively the rate of willingness to accept MaaS in this study.

Indeed, the MaaS concept is still recent and incipient. Therefore, further studies should analyse aspects related to the integration of actors (considering Autonomous Vehicles) and the MaaS ecosystem. Also, the implementation of a MaaS scheme (specificities and strategies) in a developing country should be considered. However, this study provides, as far as we know, a first step to understand the willingness to use MaaS in a developing country.

\section{ACKNOWLEDGEMENTS}

This paper would not have been possible without the support of the Laboratoire Génie Industriel (LGI/CentraleSupélec - France), the Post-Graduate Program in Administration of Federal University of Lavras (PPGA/UFLA - Brazil), and the Statistics Department of Federal University of Lavras (DES/UFLA - Brazil). We also would like to thank the founding institutions: Coordenação de Aperfeiçoamento de Pessoal de Nível Superior (CAPES - Brazil) and Fundação de Amparo de Pesquisa de Minas Gerais (Fapemig - Brazil).

\section{REFERENCES}

[1] Urry, J., The 'system' of automobility. Theory, Culture \& Society, pp. 25-39, 2004.

[2] Schuppan, J., Kettner, S., Delatte, A., \& Schwedes, O., Urban multimodal travel behaviour: towards mobility without a private car. Transportation Research Procedia, $\mathbf{4}$, pp. 553-556, 2014.

[3] Epprecht, N., Von Wirth, T., Stünzi, C., \& Blumer, Y. B., Anticipating transitions beyond the current mobility regimes: how acceptability matters. Futures, 60, pp. 30-40, 2014.

[4] Stern, N., \& Stern, N. H., The Economics of Climate Change: The Stern Review. Cambridge University Press, 2007.

[5] Cao, Y., \& Wang, N., Toward efficient electric-vehicle charging using VANET-based information dissemination. IEEE Transactions on Vehicular Technology, 66(4), pp. 2886-2901, 2017.

[6] Ambrosino, G., Nelson, J.D., Boero, M., Pettinelli, I., Enabling intermodal urban transport through complementary services: from flexible mobility services to the shared use mobility agency. Research in Transportation Economics, 59, pp. 179-184, 2016.

[7] Croce A.I., Musolino G., Rindone C. \& Vitetta A., Sustainable mobility and energy resources: a quantitative assessment of transport services with electrical vehicles, Renewable and Sustainable Energy Reviews, 2019.

[8] Fishman, E., Washington, S. \& Haworth, N., Bike share's impact on car use: evidence from the United States, Great Britain, and Australia. Transportation. Research Part D: Transport and Environment., 31, pp. 13-20, 2014.

[9] Martin, E., Shaheen, S. A., \& Lidicker, J., Impact of carsharing on household vehicle holdings: results from North American shared-use vehicle survey. Transportation Research Record, 2143(1), pp. 150-158, 2010.

[10] Wong, Y.Z., Hensher, D.A. \& Mulley, C., Emerging transport technologies and the modal efficiency framework: a case for mobility as a service (MaaS). Presented at 15th International Conference on Competition and Ownership in Land Passenger Transport (Thredbo 15). Stockholm, Sweden, 2017. 
[11] Jittrapirom, P., Caiati, V. Feneri, A., Ebrahimigharehbaghi, S., Alonso-González, M. J. \& Narayan, J., Mobility as a Service: a critical review of definitions, assessments of schemes, and key challenges. Urban Planning, 2(2), pp. 13-25, 2017.

[12] Mulley, C., Mobility as a Services (MaaS) - does it have critical mass? Transport Reviews, 37(3), pp. 247-251, 2017.

[13] Kamargianni, M., Li, W., Matyas, M. \& Schäfer, A., A critical review of new mobility services for urban transport. Transportation Research Procedia, 14, pp. 3294-3303, 2016.

[14] Hietanen, S., Mobility as a service - the new transport model? Eurotransport, 12(2), pp. $2-4,2014$.

[15] Hensher, D.A., Future bus transport contracts under a mobility as a service (MaaS) regime in the digital age: are they likely to change? Transportation Research Part A, 98, pp. 86-96, 2017.

[16] Matyas, M., \& Kamargianni, M., A stated preference experiments for Mobility as a Service plans. Presented at 5th IEEE International Conference on Models and Technologies for Intelligent Transportation Systems (MT-ITS), pp. 738-743, 2017.

[17] Datson, J., Mobility as a Service: Exploring the Opportunity for Mobility as a Service in the UK. Online https://ts.catapult.org.uk/wp-content/uploads/2016/07/Mobility as a Service_Exploring-the-Opportunity-for-MaaS-in-the-UK-Web.pdf, 2016. Accessed on: 20 Aug. 2018.

[18] MaaS Alliance, (2019), https://maas-alliance.eu/ (accessed on november 2020)

[19] Hannon, E., McKerracher, C., Orlandi, I., \& Ramkumar, S., An integrated perspective on the future of mobility. McKinsey Report October, 2016.

[20] Lyons, G., Hammond, P., \& Mackay, K., The importance of user perspective in the evolution of MaaS. Transportation Research Part A: Policy and Practice, 121, pp. 22-36, 2019.

[21] Antonialli, F., Business platforms for automated driving systems: a product-service system approach for mobility as a service. [Doctoral dissertation], UFLA, Lavras, Brazil, 2018.

[22] Jittrapirom, P., Marchau, V., van der Heijden, R., \& Meurs, H., Future implementation of Mobility as a Service (MaaS): results of an international Delphi study. Travel Behaviour and Society, 2018.

[23] Shaheen, S. A., Chan, N. D., \& Gaynor, T., Casual carpooling in the San Francisco Bay Area: understanding user characteristics, behaviors, and motivations. Transport Policy, 51, pp. 165-173, 2016.

[24] Maltzman, F., Casual carpooling: an update, RIDES for Bay Area Commuters, San Francisco., 1987

[25] Chan, N. D., \& Shaheen, S. A., Ridesharing in North America: past, present, and future. Transport reviews, 32(1), pp. 93-112, 2012.

[26] Aaker, D. A., Kumar, V. \& Day, G. S., Pesquisa de marketing, Atlas, São Paulo, 2001.

[27] Malhotra, N., Pesquisa de marketing: uma orientação aplicada, Bookman, Porto Alegre, Brazil, 2001.

[28] Hair Jr., J. F., Análise Multivariada de Dados, Bookman, Porto Alegre, Brazil, 2005.

[29] Breiman L., Friedman J. H., Olshen R. A., \& Stone, C. J., Classification and Regression Trees. Wadsworth, 1984.

[30] R Core Team., R: A Language and Environment for Statistical Computing. R Foundation for Statistical Computing, Vienna, Austria, 2018. 
[31] Therneau, T. \& Atkinson, B., rpart: Recursive Partitioning and Regression Trees. $R$ package version 4.1-13., 2018.

[32] Milborrow, S., rpart.plot: Plot 'rpart' Models: An Enhanced Version of 'plot.rpart'. $R$ package version 3.0.6., 2018.

[33] Moore, G. C., \& Benbasat, I., Development of an instrument to measure the perceptions of adopting an information technology innovation. Information Systems Research, 2(3), pp. 192-222, 1991.

[34] Davis, F. D., Perceived Usefulness, Perceived Ease of Use, and User Acceptance of Information Technology. MIS quarterly, pp. 319-340, 1989.

[35] Dantan, S., Bulteau, J., \& Nicolaï, I., Enhancing sustainable mobility through a multimodal platform: would travelers pay for it?, International Journal of Sustainable Development, 20(1-2), pp. 33-55, 2017.

[36] Gandia, R. M., Oliveira, J. R., Antonialli, F., Sugano, J. Y., Nicolaï, I. \& Oliveira, I. R. C., Consumer predisposition and behavior towards mobility-as-a-service among university students in a developing country. Presented at 25th International Conference on Urban Transport and the Environment, Urban Transport, Aveiro, 2019.

[37] Nelson, A., \& Harvey, F. A., Technologies for training and supporting your agile workforce. Presented at 4th Agility Forum Annual Conference - Creating the Agile Organization: Models, Metrics and Pilots, 1995

[38] Dove, R., The Meaning of Life and the Meaning of Agile. Production Magazine, 1994.

[39] Kamau, J., Ahmed, A., Rebeiro-H, A., Kitaoka, H., Okajima, H., \& Ripon, Z. H., Demand responsive mobility as a service. Presented at IEEE International Conference on Systems, Man, and Cybernetics (SMC), pp. 001741-001746, 2016.

[40] Nikitas, A., Understanding bike-sharing acceptability and expected usage patterns in the context of a small city novel to the concept: a story of 'Greek Drama'. Transportation Research Part F: Traffic Psychology and Behaviour, 56, pp. 306-321, 2018.

[41] Utriainen, R., \& Pöllänen, M., Review on mobility as a service in scientific publications. Research in Transportation Business \& Management, 2018.

[42] Magaudda, P., When materiality 'bites back': digital music consumption practices in the age of dematerialization. Journal of Consumer Culture, 11(1), pp. 15-36, 2011. 